\title{
Reversible operculum syndrome caused by progressive epilepsia partialis continua in a child with left hemimegalencephaly
}

\author{
Lucia Fusco, Federico Vigevano
}

\begin{abstract}
In a child with left hemimegalencephaly and seizures, a reversible operculum syndrome developed when continuous epileptic discharges spread from the left hemisphere to the contralateral central regions. The operculum syndrome lasted for three months until left hemispherectomy was performed. Soon after surgery the seizures and the operculum syndrome resolved. The operculum syndrome is a facio-pharyngo-glossomasticatory diplegia usually due to structural lesions in both opercular regions. The reversibility of the syndrome in the reported case demonstrates that the operculum syndrome is sometimes functional rather than lesional.
\end{abstract}

The clinical entity known as the operculum syndrome $^{1}$ or Foix-Chavany-Marie syndrome $^{2}$ is a facio-pharyngo-glosso-masticatory diplegia caused by lesions in both opercular regions, presenting as a cortical pseudobulbar palsy. Most reported cases were caused by vascular lesions. ${ }^{3-7}$ A congenital operculum syndrome has recently been described in patients with neuronal migration abnormalities, such as bilateral perisylvian dysplasia. $^{8-11}$ We observed the operculum syndrome in a child with left hemimegalencephaly and epilepsia partialis continua when epileptic discharges, originating from the dysplastic hemisphere, affected contralateral central regions. The clinical picture of the operculum syndrome began slowly but gradually worsened and lasted for three months until the child had a hemispherectomy, after which she recovered promptly and completely.

Neurophysiology, Bambino Gesù Children's Hospital, National Medical Research Institute, Rome, Italy L Fusco F Vigevano

Correspondence to: Dr Vigevano, Section of Neurophysiology, Bambin Geurophysiology, Bambino Gesu Children's Hospital National Medical Research
Institute, Piazza S Onofrio 4 00165 Rome, Italy

Received 3 August 1990 and in revised form

Accepted 22 November 1990 seizures with deviation of the eyes and head to the right, right hemiclonic, and convulsive generalised attacks. The child was born following an uncomplicated pregnancy and labour. A right hemiparesis was found after the first attack. She controlled her head at about four months and she sat up at 12 months. She could stand up with some help around 26 months. Intellectual development was moderately delayed: she had a severe delay in language, but she was able to communicate her needs and understand simple information from her parents.

At the age of two years she developed epilepsia partialis continua (EPC) with brief, repetitive, right-sided jerks that were particularly evident, at onset, in the hand and foot. An MRI study of the brain demonstrated the presence of abnormal gyral patterns in the left frontal, temporal and parietal lobes with increased white matter (fig 1), and showed an overgrowth of the left hemisphere, suggesting a moderate form of hemimegalencephaly.

At the age of two years and 10 months the child's clinical condition worsened. The right

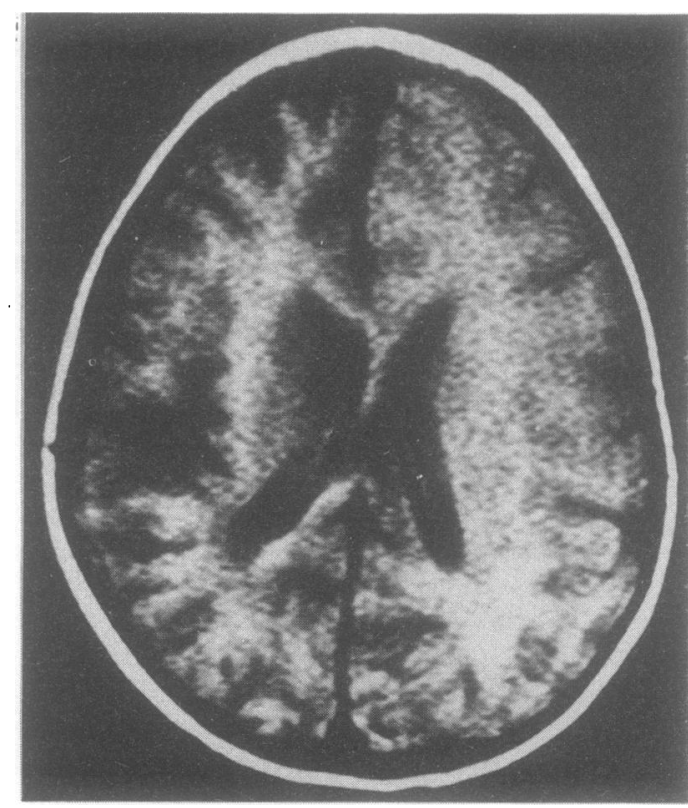

Figure 1 An axial SE 650/30 MRI after ACTH therapy, shows a shrinking of both hemispheres with right atrophy and abnormal gyral patterns in the left frontal, temporal and parietal lobes, with increased white matter. The ACTH-atrophy enhances the difference in size between the two sides; the overgrowth of the left hemisphere is evident. (The left side of the brain is on the right of the figure.)

Despite ther Despite therapy, seizures persisted and at 
Figure 2 A) EEG recorded at the age of two years and nine months shows spike and spike and wave complexes over the left hemisphere; $B$ ) at the age of three years, when the child showed the clinical features of the operculum syndrome, multiple abnormalities also appeared over the right frontal and central regions.

(A)

A.D. $2 y 9 \mathrm{~m}$ Awake 8.18 .1987

$100 \mathrm{MVL}$

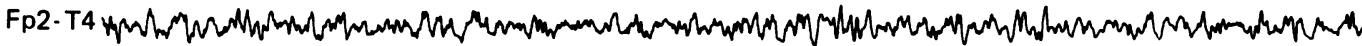

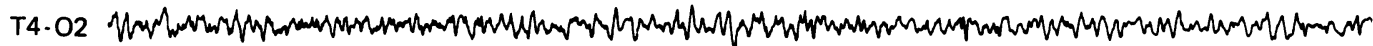

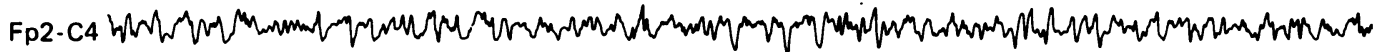

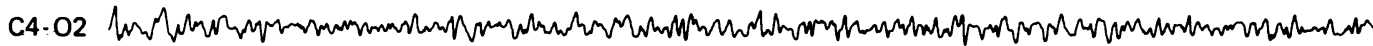

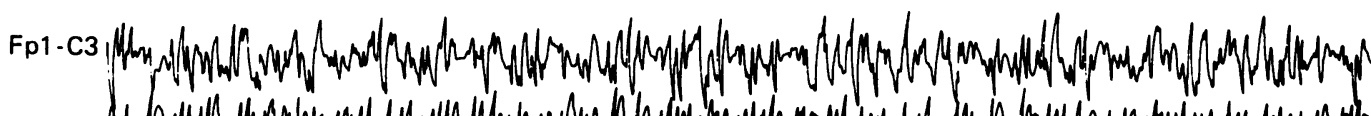

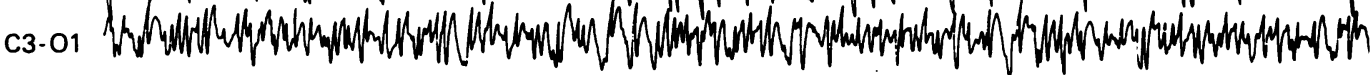

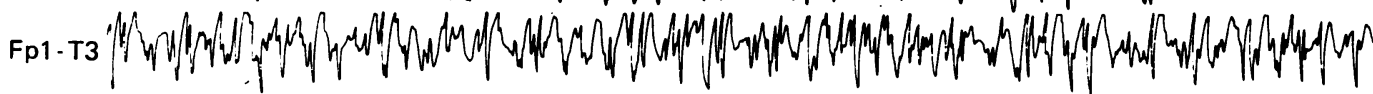

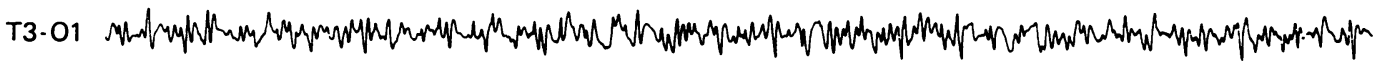

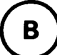
A.D. 3y Awake 11.21.1987

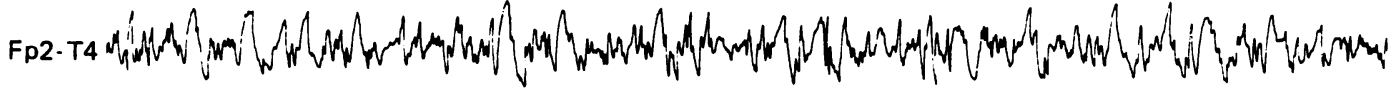

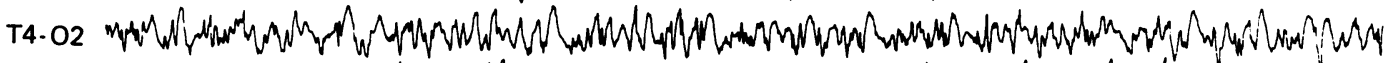

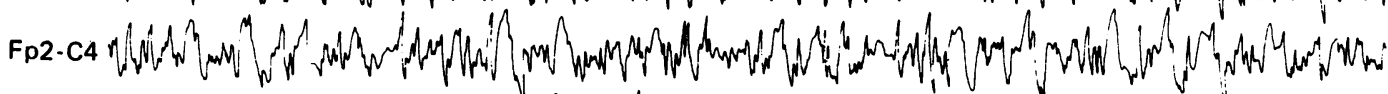

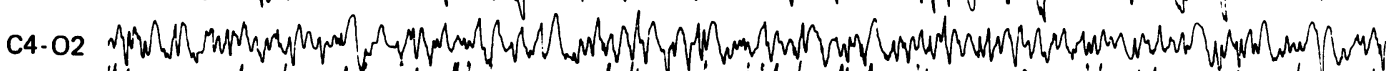
Fo1-c3 "

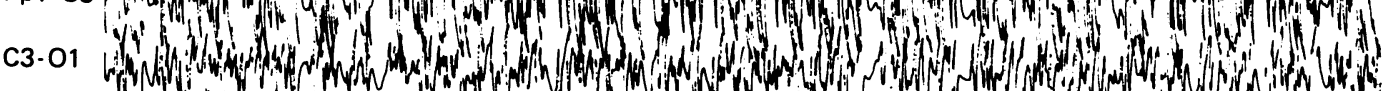
等 Fo1-T3

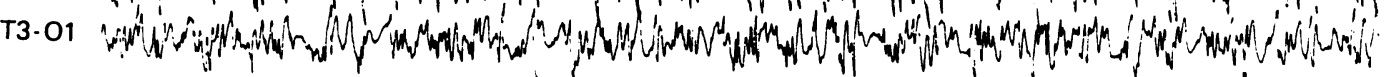
$100 \mathrm{NVL}$

sided jerks involved a larger body area, including the right arm and leg, and right facial muscles. The right hemiparesis became worse. Spike and spike-and-wave complexes in the EEG, which were previously confined to the left hemisphere, also appeared over the contralateral right frontal and central regions (fig 2). She had lost voluntary control of facial, pharyngeal, lingual and masticatory muscles while automatic functions seemed to be preserved. She could yawn but she could not open her mouth or move her tongue on command. Crying was monotonous and low. She had severe difficulty in chewing and swallowing, and an expressionless facies. Her level of consciousness was not impaired. In the following weeks, brief but subcontinuous jerks also became evident in the left facial muscles and left hand. She also showed fewer voluntary movements on the left side but could, nevertheless, move on command. Her general condition deteriorated rapidly and in January 1988 , at the age of three years and two months, she had a left hemispherectomy. Immediately after surgery the clinical epileptic manifestations disappeared. The symptoms and signs of the operculum syndrome also disappeared soon after surgery: on the second postoperative day she could already smile at her parents, and form a kiss with her lips, in spite of a clear right facial paresis. She could eat and swallow without difficulty. On EEG, epileptiform activity was no longer present over the right hemisphere. She completely recovered her ability to chew after one month. Despite deterioration of the right hemiparesis after surgery, she could stand with some help six months after surgery, and she was able to walk after 10 months. Language improved rapidly, and she can now say complete phrases, and is able to read letters and simple words. A microscopical examination of histological sections from different parts of the left hemisphere confirmed a dysplastic lesion and showed thickening grey matter, lack of horizontal layers and chaotic distribution of neurons, which appeared giant in size. She was seizure-free until 17 months later, when she had a cluster of right hemitonic seizures, which remitted with phenytoin.

\section{Discussion}

Since Foix, Chavany and Marie in $1926^{2}$ described the operculum syndrome as a facio- 
pharyngo-glosso-masticatory diplegia in two patients with bilateral vascular lesions of the anterior operculum, 28 vascular cases have been reported; $;^{5-7}$ all but one were caused by multiple strokes and the symptoms appeared after the second or the third infarct. A congenital operculum syndrome has also been described in patients with bilateral central dysplasia. $^{8-11}$ In these cases, the operculum syndrome was clinically evident even in the neonatal period and became more apparent in infancy. The MRI study showed bilateral perisylvian cortical polymicrogyria, ${ }^{8}$ bilateral open opercular malformation, ${ }^{9}$ and bilateral central macrogyria; ${ }^{10}$ in one study, ${ }^{11}$ opercular polymicrogyria was demonstrated by neuropathology.

Operculum syndrome due to unilateral opercular damage has also been described ${ }^{12-14}$ but, in these cases the clinical symptomatology is also unilateral, resembling unilateral palsy of multiple cranial nerves, being therefore clinically different from the classic picture of operculum syndrome, and from our case.

To our knowledge there are no reports of a reversible operculum syndrome due to a temporary malfunction of one opercular region, in the presence of pre-existing contralateral opercular damage. Our case had unilateral megalencephaly, which is a rare dysplastic disorder, characterised by overgrowth of part or all of a cerebral hemisphere with abnormal neuronal migration in the affected areas. ${ }^{15}$ Patients present with various degrees of intellectual impairment, depending on the extent of the cerebral abnormalities, and contralateral hemiparesis. The lesion is generally highly epileptogenic and when the epilepsy is intractable, hemispherectomy is the treatment of choice. ${ }^{16}$ The operculum syndrome is not a clinical feature of this malformation.

In addition to partial and generalised seizures, our patient also had EPC, which was refractory to treatment and progressive in nature. The EEG abnormalities, which in the first years of life were confined to the left hemisphere because of the underlying malformation, spread to the contralateral central regions within several months from the onset of EPC. In that period bulbar functions were lost completely, and the child developed operculum syndrome; subsequently jerks also became evident in the left side of the face and arm. After the removal of the epileptogenic tissue; EPC disappeared and bulbar functions were regained, demonstrating the anatomical integrity of the previously impaired regions.

Although epilepsia partialis continua with bilateral clinical manifestations has been described, ${ }^{17}$ operculum syndrome has not been reported in these cases.

Our case, one of the few reports of the operculum syndrome in a child, has an unusual aetiology, unlike that described in adults and older children. In this three year old child, the syndrome was completely reversible, suggesting a functional nature.

1 Bruyn GW, Gathier JC. The operculum syndrome. In Vinken PJ, Bruyn GW, eds. Handbook of clinical neurology, Vol

2 Foix C, Chavany JA, Marie J. Diplegie facio-linguo-masticatrice d'origine cortico sous-corticale sans paralysie de membres. Rev Neurol 1926;33:214-19.

3 Chateau R, Fau R, Groslambert R, Perret J, Boucharlat J Chatelain $R$. A propos de trois observations de diplegie linguo-facio-masticatrice d'origine corticale: la forme de l'adulte et celle de l'enfant. Rev Neurol 1966;114:390-5.

4 Ferrari G, Boninsegna C, Beltramello A. Foix-Chavany syndrome: CT study and clinical report of three cases. Neuroradiology 1979;18:41-2.

5 Mariani C, Spinnler H, Sterzi R, Vallar G. Bilatera perisylvian softenings: bilateral anterior opercular syndrome (Foix-Chavany-Marie syndrome). J Neurol 1980; 223:269-84.

6 Villa G, Caltagirone C. Speech suppression without aphasia after bilateral perisylvian softenings (bilateral rolandic after bilateral perisylvian softenings (bilateral rolan
operculum damage). Ital J Neurol Sci 1984;V:77-83.

7 Mao CC, Coull BM, Golper LAC, Rau MT. Anterior operculum syndrome. Neurology 1989;39:1169-72.

8 Graff-Radford NR, Bosh EP, Stears JC, Tranel D. Developmental Foix-Chavany-Marie syndrome in identical twins. Ann Neurol 1986;20:632-5.

9 Tatum WO, Coker SB, Ghobrial M, Abd-Allah S. The open opercular sign: diagnosis and significance. Ann Neurol 1989;25:196-9.

10 Kuzniecky R, Andermann F, Tampieri D, Melanson D, Olivier A, Leppik I. Bilateral central macrogyria: epilepsy, pseudobulbar palsy, and mental retardation-A recognizable neuronal migration disorder. Ann Neurol 1989;25:547-54.

11 Becker PS, Dixon AM, Troncoso JC. Bilateral opercular polymicrogyria. Ann Neurol 1989;25:90-2.

12 Alajouanine TH, Boudin G, Pertuiset B, Pépin B. Le syndrome operculaire unilateral avec atteinte consyndrome operculaire unilateral avec atteinte controlaterale du territoire des V, VII, IX,

13 Boudin G, Pépin B, Wiart JP. Le syndrome operculair unilatéral d'origine vasculaire. Rev Neurol 1969;103:15.

14 Pertuiset B, Perrier F. Le syndrome operculaire unilatéra (rolandique inférieur) d'origine vasculaire. Rev Neurol 1969;103:63-4

5 Barkovich AJ, Chuang SH, Norman D. MR of neuronal migration anomalies. $A J N R$ 1987;8:1009-17.

16 Vigevano F, Bertini E, Boldrini R, et al. Hemimegalencephaly and intractable epilepsy: benefits of hemispherectomy. Epilepsia 1989;30:833-43.

17 Bancaud J, Bonis A, Trottier S, Talairach J, Dulac O. L'epilepsie partielle continue: syndrome et maladie. $R e v$ Neurol 1982;138:803-14. 